\title{
'Teach-back' is a simple communication tool that improves disease knowledge in people with chronic hepatitis $B$ - a pilot randomized controlled study
}

Sophie $\operatorname{Tran}^{1,2^{*}}$ (1) Gabrielle Bennett ${ }^{1,2}$, Jacqui Richmond ${ }^{1,2,3}$, Tin Nguyen ${ }^{1,2}$, Marno Ryan ${ }^{1,2}$, Thai Hong ${ }^{1,2}$, Jessica Howell ${ }^{1,2}$, Barbara Demediuk ${ }^{1,2}$, Paul Desmond ${ }^{1,2}$, Sally Bell ${ }^{1,2}$ and Alexander Thompson ${ }^{1,2^{*}}$

\begin{abstract}
Background: The low diagnosis rate and poor access to clinical care among people with CHB is a major barrier to reducing HBV-related morbidity and mortality in Australia. One explanation for this is a lack of disease-specific knowledge among people living with CHB. Health literacy has been shown to be important for maximising engagement with medical care and adherence to recommended management. The 'teach-back' communication strategy has been shown to improve patient understanding in other clinical areas. This study aims to assess diseasespecific knowledge; and evaluate the efficacy of the teach-back strategy for improving HBV knowledge, compared to a standard medical consultation.
\end{abstract}

Method: A randomized pilot study was conducted between February and June 2017. Participants were recruited from the liver clinic at an inner-city tertiary hospital. English-speaking patients aged $\geq 18$ years and diagnosed with CHB were eligible for the study. Participants were randomised to a control group (medical specialist appointment) and intervention group (teach-back). Knowledge was assessed at baseline, immediately post-intervention and at one month using a validated questionnaire. Participants in the intervention group received a one-on-one teachback session about CHB. The main outcome measure was a combined knowledge score of the domains assessed transmission, natural history, epidemiology and prevention and clinical management.

Results: Seventy participants were recruited (control $n=32$, teach-back $n=38$ ). Mean baseline knowledge score was 19.1 out of 23 with 55 (79\%) participants scoring $\geq 17.3$ (defined as high knowledge) (7). Sub-analysis of CHB knowledge domains identified focal deficits concerning transmission and whether HBV is curable. Knowledge scores were found to be positively associated with English proficiency and antiviral treatment experience $(p<0.05)$. Teachback was associated with a significant increase in CHB knowledge at early recall (22.5 vs 18.7, $p<0.001)$ and at 1 month follow-up (21.9 vs 18.7, $\mathrm{p}<0.001$ ); there was no improvement in CHB knowledge associated with standard clinical consultant (early recall: 19.6 vs 19.4, $p=0.49$, one-month follow-up: 19.5 vs 19.4, $p=0.94$ ).

Conclusion: In a tertiary hospital liver clinic population, baseline knowledge about CHB was good, but there were focal deficits concerning transmission and potential for cure. Teach-back was associated with improvement in CHB knowledge and it is a simple communication tool suitable for incorporation into a standard medical consultation.

Keywords: Health literacy, HBV, Teach-back, Education, Communication, Liver, Cirrhosis, This study has been retrospectively registered with the Australian and New Zealand Trials Registry on 29th March 2019 - ACTR N12619000512123.

\footnotetext{
*Correspondence: sophie.tran@svha.org.au; alexander.thompson@svha.org.au

'Department of Gastroenterology, St. Vincent's Hospital Melbourne, Level 4

Daly Wing, 35 Victoria Parade, Fitzroy, Victoria 3065, Australia

Full list of author information is available at the end of the article
}

(c) The Author(s). 2019 Open Access This article is distributed under the terms of the Creative Commons Attribution 4.0 International License (http://creativecommons.org/licenses/by/4.0/), which permits unrestricted use, distribution, and reproduction in any medium, provided you give appropriate credit to the original author(s) and the source, provide a link to the Creative Commons license, and indicate if changes were made. The Creative Commons Public Domain Dedication waiver (http://creativecommons.org/publicdomain/zero/1.0/) applies to the data made available in this article, unless otherwise stated. 


\section{Background}

Over 200,000 Australians were estimated to be living with chronic hepatitis B (CHB) in 2011, with higher rates in Aboriginal and Torres Strait Islander and culturally and linguistically diverse (CALD) communities [1]. CHB is a major cause of mortality; responsible for $53 \%$ of hepatocellular carcinomas (HCC) worldwide [2] and is increasingly recognised to cause significant morbidity and mortality within Australia where liver cancer is now the fastest growing case of cancer-related deaths [3]. A low diagnosis rate [1] and poor access to clinical care [4] among people living with $\mathrm{CHB}$ is a major barrier to reducing $\mathrm{CHB}$-related morbidity and mortality. One explanation for this is poor disease-related knowledge among people living with $\mathrm{CHB}$.

Health literacy (HL) is important for maximising engagement with medical care and adherence to recommended management $[5,6]$. Studies assessing disease-related knowledge among Australians living with $\mathrm{CHB}$ have revealed gaps in patient understanding, particularly concerning modes of transmission, clinical management and consequences of $\mathrm{CHB}$ beyond the liver [7-9]. Despite current literature identifying knowledge gaps amongst patients with $\mathrm{CHB}$, few studies have evaluated the effectiveness of an educational intervention in people already diagnosed with $\mathrm{CHB}$. Educating people living with $\mathrm{CHB}$ could lead to improved coping mechanisms and empowerment to actively participate in their clinical management. Adherence to recommendations concerning prevention of transmission (family screening and vaccination, prevention of sexual transmission), monitoring (virological and HCC screening) and treatment (long-term antivirals) are particularly important to improving long-term outcomes of the individual and the community.

The current literature suggests that up to $40-80 \%$ of medical information is forgotten immediately and much of the information that is recalled is inaccurately retained [10]. One intervention that has been shown to be effective for improving information retention and understanding is the teach-back method [11-17]. Teachback encourages healthcare providers to ask patients to explain, in their own words, the information that has been covered. If the patient is unable to recall or has difficulty understanding the information, the provider can identify specific misunderstandings/deficits and reexplain the concept. The benefits of teach-back have not yet previously been studied in the hepatitis B setting. Therefore, the aims of this study were to:

i) Assess baseline knowledge in people living with $\mathrm{CHB}$;

ii) Evaluate the efficacy of the teach-back method for improving $\mathrm{CHB}$ knowledge, compared to a standard medical consultation.

\section{Method}

\section{Trial design}

This was a randomised, parallel group, two arm pilot study with an allocation ratio of $1: 1$.

\section{Patient cohort}

In this randomised controlled trial, adults living with $\mathrm{CHB}$ referred to and attending the outpatient liver clinic at a Melbourne tertiary hospital were recruited between February and June 2017. Patients aged 18 years or older living with $\mathrm{CHB}$ and compensated liver disease were eligible for the study. Chronically infected was defined as HBsAg-positive for greater than 6 months. Recruitment of participants requiring an interpreter was piloted, but for logistic reasons the decision was made to focus on patients who were English-speaking by self-assessment. The results of the four participants who were interviewed with an interpreter were included in the final analysis. The barriers to interpreter access were cost and increased consultation time within a fixed recruitment period.

\section{Study procedure}

All eligible patients were approached in the outpatient waiting rooms before their appointments and invited to participate in the study by the author (ST). Sociodemographic details were collected and the study questionnaire was administered to measure baseline knowledge. Participants were then randomised into the standard consult (control) or teach-back (intervention) group. A softwaregenerated randomisation software (SAS V9.2) was used to create an allocation sequence to assign patients to the two study arms by the principal investigator (AT). The allocation sequence was concealed to the investigator recruiting patients and administering teach-back (ST). The CHB questionnaire was administered to participants immediately following their respective consultation and again at four weeks after the initial educational intervention (teach-back vs standard consult) over the phone. The main outcome measure was a combined knowledge score of the domains assessed - transmission, natural history, epidemiology and prevention and clinical management.

\section{Study questionnaire}

A modified validated questionnaire (Additional files 1 and 2) was used in this study [7]. The first part of the questionnaire was a baseline survey to obtain sociodemographic details of participants (Additional file 1). The $\mathrm{CHB}$ questionnaire (Additional file 2) consisted of 23 true or false statements assessing hepatitis B knowledge scores across four domains: transmission (nine questions), natural history (five questions), epidemiology and prevention (five questions) and clinical management (four questions). The questionnaire was administered: i) at baseline; ii) immediately postintervention to test early recall; and iii) 4 weeks post- 
intervention to test late recall. A knowledge score of $\geq 17.3$ (75\%) was considered as high knowledge and a score between 12.7-17.3 (55-75\%) as intermediate level, as defined by previous study [7].

\section{Control and intervention}

Participants in the control group attended their scheduled routine appointment with a gastroenterologist or gastroenterology advanced trainee registrar. A standard consult for a patient would involve reviewing their progress, recent investigations and if applicable, treatment regime. Participants in the intervention group received a once-off education session run by a trained investigator (ST) using the teach-back strategy. This session involved a discussion between the investigator and participant on the four domains of $\mathrm{CHB}$ - transmission, natural history, epidemiology and prevention and clinical management; supported by simple explanations and images using an educational resource specifically developed for people with low health literacy (The Hepatitis B Story [18]). Information was explained using plain language and medical jargon avoided. After covering each concept, the investigator would use teach-back to confirm patient understanding, for example: 'To check that I have explained the information clearly, could you please tell me how hepatitis B is spread?'. If the answers were wrong or incomplete, the investigator would re-explain the concept and reassess until the participant understood the information.

\section{Statistical analysis}

Overall knowledge was scored out of 23, based on answers to all of the questions across the four domains. One point was given for correct answers and zero for incorrect or a 'do not know' answer. Descriptive statistics were reported as mean \pm standard deviation (SD) or median (interquartile range) for continuous data, and statistical summaries were reported as counts and percentages of participants with a positive response for categorical data.

Group equivalence was assessed by the Chi-square test and Fisher exact test on categorical variables and independent sample t-test on continuous variables. The intervention and control group knowledge scores were compared by paired $t$-test and analysis of variance (ANOVA) for normally distributed data and by Wilcoxon signed rank test for nonnormally distributed data. Linear regression was conducted to detect associations between knowledge scores and sociodemographic characteristics. Variables that reached statistical significance $(p \leq 0.05)$ and those that showed a trend towards association with knowledge score $(p \leq 0.1$ was accepted), were included in the multivariate model.

All analyses were performed on an intent-to-treat basis and included all enrolled participants. In all cases, comparisons were two-tailed and a $p$-value of $\leq 0.05$ was considered statistically significant. Data was analysed using SPSS software version 23 (IBM, New York, 2015).

\section{Results \\ Participant characteristics}

Seventy participants were enrolled in this study within the fixed recruitment period, between February and June 2017 (control $n=32$, teach-back $n=38$, Table 1). No participants were excluded or lost at early recall, however 19 participants were lost at 1 month follow up (control: $n=8$, intervention: $n=11$ ). The majority of participants were born overseas, with $77 \%$ from Asia, 49\% self-rated their English proficiency to be very good and $78 \%$ had tertiary qualifications. Mean time since diagnosis was 13.5 years (SD:10.9) and time since first consult was 7.2 years (SD:6.5) with one participant presenting for initial consult. Two thirds of participants had previously or are currently receiving antiviral treatment.

\section{Baseline hepatitis B knowledge}

The mean total pre-test knowledge score was 19.1 (2.4) out of 23. Fifty-five participants (79\%) had high level hepatitis B knowledge, scoring $\geq 17.3$. There was no difference in mean total knowledge at baseline between teach-back vs standard consultations arms (18.7 vs 19.4, $p=0.2$ ). Sub-analysis of knowledge according to the four domains of HBV knowledge revealed good knowledge (mean scores): clinical management (75\%; IQR: 75.100), natural history (100\%; IQR: 80,100$)$, transmission (78\%; IQR: 67,100$)$ and epidemiology and prevention $(80 \%$; IQR: 80,80).

Two questions answered correctly by all participants were 'people with hepatitis B should tell their family members to get tested for hepatitis B' and 'hepatitis B causes liver damage' (Table 2). Poorly answered questions included 'washing hands can prevent hepatitis B' (57\%), 'hepatitis B can be cured' (61\%) and 'Asian people are more likely to have hepatitis B' (66\%). Forty-one participants (59\%) were aware of all four transmission routes of hepatitis B (i.e. sexual and vertical transmission, sharing of injecting equipment, sharing toothbrushes and razor blades). Commonly misperceived modes of transmission included kissing (60\%) and sharing eating utensils (57\%).

\section{Factors associated with baseline hepatitis B knowledge}

Specific sociodemographic factors were correlated with baseline HBV knowledge. Linear regression analysis showed age $\leq 35$ years and very good English proficiency were associated with better knowledge (Table 3). Multivariate analysis found that participants who had selfrated very good English proficiency $(p=0.016)$ and are currently receiving or have previously received antiviral 
Table 1 Sociodemographic features of the study cohort

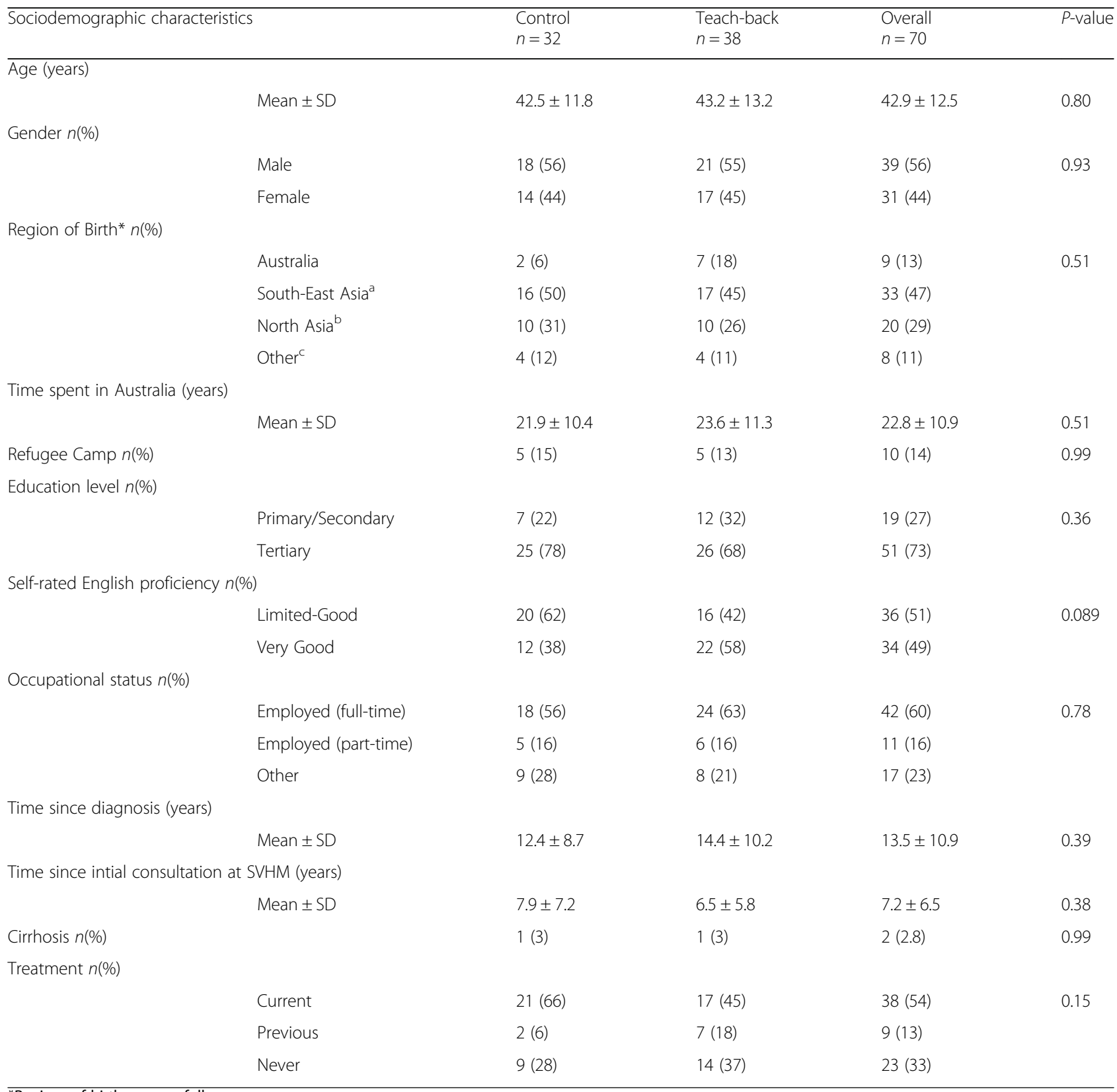

*Regions of birth were as follow:

${ }^{\text {a }}$ South-East Asia: Vietnam, Malaysia, Thailand, Indonesia, Philippines, Myanmar, Brunei, East Timor

${ }^{b}$ North Asia: China, Hong Kong, Taiwan, South Korea, Japan

'Other: France, Macedonia, India, Sudan, Mali, Pakistan, Papua New Guinea, Mauritius

treatment $(p=0.047)$, were independently associated with higher knowledge scores (Table 3).

\section{Effectiveness of teach-back}

All participants randomised to teach-back received a dedicated hepatitis $B$ education session in which the teach-back communication technique was used to reinforce and test knowledge retention. Median time taken to deliver a teach-back education session was 15 min (IQR: 12, 22). Hepatitis B education using teach- back was associated with improvement in hepatitis $\mathrm{B}$ knowledge scores. Participants in the teach-back group scored higher in the post-test compared to baseline (22.5 vs $18.7, p<0.001)$. There was no improvement in hepatitis B knowledge associated with the standard clinical consultation (19.6 vs $19.4, p=0.49)$. There were significant improvements across all four domains assessed within the teach-back group (Table 4).

Following teach-back, all participants scored $100 \%$ in the natural history domain and correctly identified that 
Table 2 Baseline Knowledge - Proportion of participants correctly answered HBV questions

\begin{tabular}{|c|c|c|c|}
\hline Questions & $\begin{array}{l}\text { Control } \\
n=32\end{array}$ & $\begin{array}{l}\text { Teach-back } \\
n=38\end{array}$ & $\begin{array}{l}\text { Overall } \\
n=70\end{array}$ \\
\hline Transmission routes & $N(\%)$ & $N(\%)$ & $N(\%)$ \\
\hline By having unprotected sex with a person with hepatitis B (true) & $26(81)$ & $30(79)$ & $56(80)$ \\
\hline Through mother to child at birth (true) & $29(91)$ & $28(74)$ & $57(81)$ \\
\hline By touching a person with hepatitis B (false) & $31(97)$ & $35(92)$ & $66(94)$ \\
\hline By kissing a person with hepatitis B (false) & $21(66)$ & $21(55)$ & $42(60)$ \\
\hline By eating food prepared and cooked by a person with hepatitis B (false) & $27(84)$ & $30(79)$ & $57(81)$ \\
\hline Through the air when a person with hepatitis B coughs or sneezes (false) & $26(81)$ & $36(95)$ & $62(89)$ \\
\hline By sharing eating utensils (false) & $17(53)$ & $23(61)$ & $40(57)$ \\
\hline By sharing toothbrushes or razor blades (true) & $28(88)$ & $31(82)$ & $59(84)$ \\
\hline By sharing injecting equipments, e.g. Needles used in acupuncture, tattooing, body piercing or drug use (true) & $32(100)$ & $37(97)$ & $69(99)$ \\
\hline \multicolumn{4}{|l|}{ Natural history } \\
\hline Hepatitis B can cause liver damage (true) & $32(100)$ & $38(100)$ & $70(100)$ \\
\hline Hepatitis B can cause liver cancer (true) & $29(91)$ & $33(87)$ & $62(89)$ \\
\hline Most people infected with hepatitis b have no symptoms (true) & $25(78)$ & $28(74)$ & $53(76)$ \\
\hline People with hepatitis B can be infected for life (true) & $29(91)$ & $36(95)$ & $65(93)$ \\
\hline Alcohol further damages the liver for people with hepatitis B (true) & $31(97)$ & $35(92)$ & $66(94)$ \\
\hline \multicolumn{4}{|l|}{ Epidemiology and prevention } \\
\hline Asians are more likely to be infected with hepatitis B than other people (true) & $22(69)$ & $24(63)$ & $46(66)$ \\
\hline There is a vaccination to prevent hepatitis B (true) & $28(88)$ & $35(92)$ & $63(90)$ \\
\hline Washing hands before eating prevents getting hepatitis B (false) & $19(59)$ & $21(55)$ & $40(57)$ \\
\hline People with hepatitis B should use condoms when having sex (true) & $30(94)$ & $31(82)$ & $61(87)$ \\
\hline People with hepatitis B should tell their family members to get tested (true) & $32(100)$ & $38(100)$ & $70(100)$ \\
\hline \multicolumn{4}{|l|}{ Clinical management } \\
\hline Hepatitis B can be cured (false) & $20(63)$ & $23(61)$ & $43(61)$ \\
\hline There are effective treatments for hepatitis B (true) & $28(88)$ & $34(90)$ & $62(89)$ \\
\hline Hepatitis B can be cured by taking traditional Chinese medicine (false) & $31(97)$ & $32(84)$ & $61(87)$ \\
\hline Healthy people with hepatitis B do not need regular check-up (false) & $31(97)$ & $33(87)$ & $64(91)$ \\
\hline
\end{tabular}

sharing eating utensils was not a transmission route. A greater proportion of participants correctly answered questions identified to expose focal deficits in knowledge at baseline following teach-back: 'washing hands before eating prevents hepatitis B' (teachback: 95\% vs baseline: 61\%) (false) and kissing is a mode of transmission (teachback: 97\% vs baseline: 55\%) (false).

\section{Late recall}

Fifty-one participants (control: $n=24$, intervention: $n=$ 27) successfully completed the 1-month follow-up. Nineteen participants were lost to follow up (control: $n=8$, intervention: $n=11$ ); there was a maximum of five attempts to contact participants in the week of their scheduled follow-up phone call. In the teach-back group, knowledge scores declined at 1-month follow-up compared to early recall (median knowledge score: 22 vs 23, $p=0.03)$. However, knowledge was found to remain higher when compared to baseline (median knowledge score: 22 vs 19, $p<0.001$ ) (Table 5). The control group showed no significant change in knowledge scores both at 1-month follow-up compared to early recall (median knowledge score: 19 vs $20, p=0.72$ ) and at 1 -month compared to baseline (median knowledge score 19 vs 19.5, $p=0.65$ ).

\section{Discussion}

This is the first study to test the effectiveness of patient education using the teach-back communication technique in people living with $\mathrm{CHB}$. We have demonstrated that a short education session using this simple communication tool is associated with improvement in levels of hepatitis B knowledge.

Teach-back was effective in improving knowledge across all domains assessed. Its use was also shown to enhance information retention at 1-month post-intervention. Though 
Table 3 Regression analysis of association between HBV knowledge scores and sociodemographic features

\begin{tabular}{|c|c|c|c|c|c|c|}
\hline \multirow{2}{*}{$\begin{array}{l}\text { Sociodemographic } \\
\text { characteristics }\end{array}$} & \multirow[t]{2}{*}{$n(\%)$} & \multirow{2}{*}{$\begin{array}{l}\text { Mean Total } \\
\text { knowledge } \\
\text { score (SD) }\end{array}$} & Beta co-efficient (95\% Cl) & \multirow[t]{2}{*}{$P$-value } & Beta co-efficient (95\% Cl) & \multirow[t]{2}{*}{$P$-value } \\
\hline & & & Univariable analysis & & Multivariable analysis & \\
\hline \multicolumn{7}{|l|}{ Gender } \\
\hline Male & $39(56)$ & $18.9(2.4)$ & & & & \\
\hline Female & $31(44)$ & $19.3(2.5)$ & $0.075(-0.80,1.52)$ & 0.54 & & \\
\hline \multicolumn{7}{|l|}{ Age } \\
\hline$>35$ & $49(70)$ & $18.7(2.4)$ & & & & \\
\hline$\leq 35$ & $21(30)$ & $20(2.3)$ & $0.26(0.13,2.57)$ & 0.031 & $1.06(-1.53-2.27)$ & 0.086 \\
\hline \multicolumn{7}{|l|}{ Birth Region } \\
\hline Australia/Europe & $11(16)$ & $18.9(2.2)$ & & & & \\
\hline Asia & $54(77)$ & $19.2(2.4)$ & $-0.051(-1.85,1.23)$ & 0.69 & & \\
\hline Others & $5(7)$ & $17.6(3.4)$ & $0.25(-1.66,4.28)$ & 0.36 & & \\
\hline \multicolumn{7}{|l|}{ Time spent in Australia } \\
\hline$\leq 15$ years & $21(30)$ & $19.2(2.7)$ & & & & \\
\hline$>15$ years & $49(70)$ & $19.0(2.3)$ & $0.037(-1.07,1.45)$ & 0.76 & & \\
\hline \multicolumn{7}{|l|}{ Refugee Camp } \\
\hline Yes & $10(14)$ & $18.4(2.2)$ & & & & \\
\hline No & $60(86)$ & $19.1(2.5)$ & $0.078(-1.11,2.18)$ & 0.52 & & \\
\hline \multicolumn{7}{|l|}{ Education level } \\
\hline Secondary and under & $19(27)$ & $18.4(2.2)$ & & & & \\
\hline Tertiary & $51(73)$ & $19.3(2.5)$ & $0.15(-0.49,2.09)$ & 0.22 & & \\
\hline \multicolumn{7}{|c|}{ Self-rated English Proficiency } \\
\hline Limited-good & $36(51)$ & $18.3(2.7)$ & & & & \\
\hline Very good & $34(49)$ & $19.9(1.8)$ & $0.34(0.52,2.70)$ & 0.005 & $1.36(0.26-2.45)$ & 0.016 \\
\hline \multicolumn{7}{|l|}{ Occupational Status } \\
\hline Employed (full time) & $42(60)$ & $18.8(2.3)$ & & & & \\
\hline Other & $28(40)$ & $19.5(2.6)$ & $-0.15(-1.91,0.43)$ & 0.21 & & \\
\hline \multicolumn{7}{|c|}{ Time since diagnosis (years) } \\
\hline$\leq 10$ years & $41(59)$ & $19.0(2.0)$ & & & & \\
\hline$>10$ years & $29(41)$ & $19.1(2.7)$ & $-0.008(-1.21,1.14)$ & 0.95 & & \\
\hline \multicolumn{7}{|c|}{ Time since initial consult at SVHM } \\
\hline$\leq 5$ year & $14(20)$ & $19.3(1.9)$ & & & & \\
\hline$>5$ year & $56(80)$ & $19.0(2.5)$ & $0.048(-1.16,1.73)$ & 0.69 & & \\
\hline \multicolumn{7}{|l|}{ Treatment } \\
\hline Never & $23(32)$ & $18.5(3.1)$ & & & & \\
\hline Current/Previous & $47(68)$ & $19.3(1.9)$ & $0.17(-0.35,2.08)$ & 0.16 & $1.16(0.01-2.31)$ & 0.047 \\
\hline
\end{tabular}

there was a decline in knowledge scores between early and late recall, there was a continual improvement when compared to baseline. A regression in knowledge score at follow-up may not necessarily reflect the effect of teachback on information maintenance but rather the nature of the educational session. A large number of concepts were covered in the one session and despite this, participants continued to demonstrate a good degree of information retention.
A study assessing how doctors used teach-back revealed a selective approach based on education level, ethnic background and age [19]. A downfall to this approach is that patients who do not fit these criteria, but may benefit from teach-back, are being overlooked. Our study cohort, in some respects, represents a privileged population; with higher education and English-proficiency levels, a mean time of 7.2 years of follow up in clinic and two thirds previously or currently on treatment. Though teach-back has 
Table 4 Comparison of knowledge scores according to domain

\begin{tabular}{|c|c|c|c|c|c|}
\hline \multirow[t]{2}{*}{ Domain } & & \multirow{2}{*}{$\begin{array}{l}\text { Mean } \pm \text { SD } \\
\text { Control } n=32\end{array}$} & \multirow{2}{*}{$\begin{array}{l}P \text { - } \\
\text { value }\end{array}$} & Mean \pm SD & \multirow[t]{2}{*}{$P$-value } \\
\hline & & & & Teach-back $n=38$ & \\
\hline \multirow[t]{2}{*}{ Transmission } & Baseline & $7.4 \pm 1.3$ & \multirow[t]{2}{*}{$>0.99$} & $7.1 \pm 1.6$ & \multirow[t]{2}{*}{$<0.001$} \\
\hline & Early recall & $7.4 \pm 1.3$ & & $8.9 \pm 0.4$ & \\
\hline \multirow[t]{2}{*}{ Natural history } & Baseline & $4.6 \pm 0.7$ & \multirow[t]{2}{*}{0.03} & $4.5 \pm 0.8$ & \multirow[t]{2}{*}{$<0.001$} \\
\hline & Early recall & $4.8 \pm 0.5$ & & $5.0 \pm 0.0$ & \\
\hline \multirow[t]{2}{*}{ Epidemiology \& Prevention } & Baseline & $4.1 \pm 0.6$ & \multirow[t]{2}{*}{$>0.99$} & $3.9 \pm 0.7$ & \multirow[t]{2}{*}{$<0.001$} \\
\hline & Early recall & $4.1 \pm 0.6$ & & $4.8 \pm 0.5$ & \\
\hline \multirow[t]{2}{*}{ Clinical Management } & Baseline & $3.4 \pm 0.7$ & \multirow[t]{2}{*}{0.68} & $3.2 \pm 0.9$ & \multirow[t]{2}{*}{$<0.001$} \\
\hline & Early recall & $3.3 \pm 0.9$ & & $3.8 \pm 0.5$ & \\
\hline
\end{tabular}

been mostly studied in cohorts with low health literacy; our study, which has demonstrated an significant improvement in disease understanding within a privileged cohort, would support the routine use of teach-back with all participants regardless of sociodemographic profile. Our findings also validate the recommended 'universal precautions' approach to health literacy, that is health providers should assume the default to be that everyone has some difficulty in accessing and understanding health information [20]. An Australian study reported that when solely based on education levels, more than $10 \%$ of patients were incorrectly assumed to have adequate/limited health literacy [21]. Health literacy extends beyond an individual's literacy and numeracy skills. It encompasses cognitive and social skills which influences an individual's capacity to promote and maintain good health by understanding and effectively applying health information [22].

Teach-back is a simple communication tool with a small evidence base for its successful use and our data adds to this existing literature that supports its use. Teach-back has been studied in a range of contexts such as discharge from the emergency department [15] and in chronic diseases such as diabetes [13] and asthma/COPD [17]. Across these studies, teach-back consistently showed improvement in disease-specific knowledge. Furthermore, a study comparing a brief verbal and written educational intervention with teach-back in educating hospitalised patients with asthma/ COPD on correct respiratory inhaler techniques; found teach-back to be more effective in reducing inhaler misuse and number of hospital-related events [17].

Overall our study cohort's baseline knowledge was high compared to previous studies assessing hepatitis B knowledge amongst patients living with CHB [7-9]. Notable differences between our study cohort and past studies, were exclusion of participants requiring interpreters, higher level of education, long-term clinic patients and higher self-assessed English proficiency. Similar to previous studies, English proficiency was found to be associated with higher levels of hepatitis $B$ knowledge [7]. As such, exclusion of non-English speaking patients within our study would be a large contributing factor to our study cohort's higher baseline knowledge. Our study also showed that participants who currently or have previously received antiviral therapy had higher knowledge. This may be explained by the fact that individuals who are on treatment may have had more information provided regarding indications for treatment and aim of treatment. They may also have more frequent follow-ups and therefore opportunities to engage them in health services and to address queries.

The deficits in knowledge identified concerned transmission and whether hepatitis B is curable. Understanding transmission routes is important to prevent ongoing transmission to susceptible contacts, to promote screening and vaccination among close contacts and also to improve quality of life by addressing misconceptions of transmission routes that contribute to the stigma of hepatitis B and cause social withdrawal [23]. Patients who understand that the role of antiviral therapy is not to cure but rather to suppress the virus may be more likely to appreciate the importance of adherence to medication and the need for ongoing long-term virological monitoring and engagement with HCC surveillance, all important management aspects of hepatitis $B$.

Table 5 Comparison of knowledge scores at 1-month post-intervention

\begin{tabular}{lllll}
\hline & Median (IQR) Control $n=24$ & $P$-value & Median (IQR) Teach-back $n=27$ & $19(17.75,20)$ \\
\hline Baseline & $19.5(18.25,21)$ & 0.65 & $22(21,23)$ \\
Late recall & $19(18,21.75)$ & & $23(22,23)$ \\
Early recall & $20(18,21)$ & 0.72 & $22(21,23)$ \\
Late recall & $19(18,21.75)$ & & 0.03 \\
\hline
\end{tabular}




\section{Limitations of this study}

There are a number of limitations to this study. Though a large proportion of people living with $\mathrm{CHB}$ are from CALD communities, our study cohort did not include non-English-speaking patients. Future studies should evaluate hepatitis B knowledge and the use of teachback in patients with limited health literacy, particularly in CALD communities. This is a simple education tool that would be feasible to apply with non-English speaking individuals with an interpreter. Furthermore, it would be interesting to evaluate this tool in patients newly diagnosed with hepatitis B. Engaging patients early in their disease course may increase adherence to important management aspects such as transmission precautions, monitoring and surveillance to mitigate the long-term consequences of hepatitis B. In this study, teach-back use was explored as a once-off education session; more research should explore its repeated use; the use of focussed teach-back over multiple appointments would also decrease time requirements. Finally, it will be important to evaluate how increased disease-related knowledge can translate into better health outcomes.

\section{Conclusion}

This is the first randomised controlled study to evaluate the use of teach-back to improve understanding among people living with $\mathrm{CHB}$. There was an overall high level of baseline disease knowledge in this cohort, however focal deficits in knowledge were identified. The use of teach-back was associated with significant improvement in knowledge and information retention. It is a simple communication tool that could be incorporated in standard clinical consults. Future studies should evaluate the efficacy of teach-back for improving hepatitis B knowledge in populations at risk for poor health literacy, in particular CALD communities.

\section{Supplementary information}

Supplementary information accompanies this paper at https://doi.org/10. 1186/s12889-019-7658-4.

Additional file 1. Baseline survey to obtain sociodemographic information.

Additional file 2. A modified validated questionnaire to assess knowledge on hepatitis B relating to the following domains: transmission, natural history, epidemiology and prevention and clinical management.

\section{Abbrieviations}

CALD: Culturally and linguistically diverse; CHB: Chronic hepatitis B; HBV: Hepatitis B; HCC: Hepatocellular carcinoma

\section{Acknowledgements}

This study was presented at the Australian Gastroenterology Week conference hosted by the Gastroenterology Society of Australia (GESA) in Gold Coast, Queensland, Australia in 2017. The abstract of this paper was then published in the Journal of Gastroenterology and Hepatology [24]. The authors of this study would like to thank all participants, nursing staff, clinic clerks and interpreters at the liver clinics for their time and generosity in contributing to this study.

\section{Authors' contributions}

AT, GB and JR designed the study. ST recruited patients, administered the questionnaire, facilitated the teach-back education sessions, followed up patients, analysed the results and wrote the manuscript. GB provided teachback training to ST and supervised in early sessions. AT, GB and JR assisted with statistical analysis and assisted in drafting the manuscript. TN, MR, TH, $\mathrm{JH}, \mathrm{BD}, \mathrm{PD}$ and SB assisted in the coordination of the study design and provided feedback throughout its progress. All authors have read and approved the manuscript.

\section{Funding}

No funding was obtained for this study.

\section{Availability of data and materials}

The study protocol, study questionnaire and datasets used and analysed during the current study are available from the corresponding author on reasonable request.

\section{Ethics approval and consent to participate}

The project was granted ethical approval by the Human Research and Ethics Committee at St. Vincent's Hospital (Melbourne) as low risk research (LRR 203/16). Written informed consent was gained from all participants of this study

\section{Consent for publication}

Not applicable.

\section{Competing interests}

The authors declare that they have no competing interests.

\section{Author details}

${ }^{1}$ Department of Gastroenterology, St. Vincent's Hospital Melbourne, Level 4 Daly Wing, 35 Victoria Parade, Fitzroy, Victoria 3065, Australia. ${ }^{2}$ The University of Melbourne, Grattan Street, Parkville, Victoria 3010, Australia. ${ }^{3}$ The Burnet Institute, Disease Elimination, 85 Commercial Road, Prahran, Melbourne 3004, Australia.

Received: 27 February 2019 Accepted: 20 September 2019

Published online: 23 October 2019

References

1. MacLachlan JH, Allard N, Towell V, Cowie BC. The burden of chronic hepatitis B virus infection in Australia, 2011. Aust NZJ Public Health. 2013; 37(5):416-22.

2. Perz J, Armstrong GJ, Farrington LA, Hutin YJ, Bell BP. The contribution of hepatitis $B$ and hepatitis $C$ virus infections to cirrhosis and primary liver cancer worldwide. J Hepatol. 2006:45(4):529-38.

3. MacLachlan $\mathrm{JH}$, Cowie BC. Liver cancer is the fastest increasing cause of cancer death in Australians. Med J Aust. 2012;197(9):492-3.

4. Allard N, MacLachlan JH, Cowie BC. The cascade of care for Australians living with chronic hepatitis B: measuring access to diagnosis, management and treatment. Aust NZJ Public Health. 2015;39(3):255-9.

5. DeWalt DA, Berkman ND, Sheridon S, Lohr KN, Pignone MP. Literacy and health outcomes: a systematic review of the literature. J Gen Intern Med. 2004;19(12):1228-39

6. Berkman ND, Sheridan SL, Donahue KE, Halpern DJ, Crotty L. Low health literacy and health outcomes: an updated systematic review. Ann Intern Med. 2011;155:97-107.

7. Hajarizadeh B, Wallace J, Richmond J, Ngo N, Enright C. Hepatitis B knowledge and associated factors among people with chronic hepatitis $B$. Aust NZJ Public Health. 2015:39(6):563-8.

8. Dahl TF, Cowie BC, Biggs BA, Leder K, MacLachlan JH, Marshall C. Health literacy in patients with chronic hepatitis $B$ attending a tertiary hospital in Melbourne: a questionnaire based survey. BMC Infect Dis. 2014;14:537-45.

9. Preston-Thomas A, Fagan P, Nakata Y, Anderson E. Chronic hepatitis B: care delivery and patient knowledge in the Torres Strait region of Australia. Aust Fam Physician. 2013:42(4):225-31.

10. Kessels R. Patients' memory for medical information. JR Soc Med. 2003;96(5):219-22. 
11. Nouri SS, Rudd RE. Health literacy in the 'oral exchange': an important element of patient-provider communication. Patient Educ Couns. 2015;98(5):565-71.

12. Schillinger D, Piette J, Grumbach K. Wang F, Wilson C, Daher C, et al. closing the loop: physician communication with diabetic patients who have low health literacy. Arch Intern Med. 2003;163(1):83-90.

13. Negarandeh R, Mahmoodi H, Noktehdan H, Heshmat R, Shakibazadeh E. Teach back and pictorial image educational strategies on knowledge about diabetes and medication/dietary adherence among low health literate patients with type 2 diabetes. Primary care diabetes. 2013;7(2):111-8.

14. White M, Garbez R, Carroll M. Is 'teach-back' associated with knowledge retention and hospital readmission in hospitalised heart failure patients? J Cardiovasc Nurs. 2013;28(2):137-46.

15. Griffey RT, Shin N, Jones S, Aginam N, Gross M, Kinsella Y, et al. The impact of teach-back on comprehension of discharge instructions and satisfaction among emergency patients with limited health literacy: a randomised, controlled study. J Health Commun. 2015;8(1):10-21.

16. Kandula NR, Malli T, Zei CP, Larsen E, Baker DW. Literacy and retention of information after a multimedia diabetes education program and teach-back. J Health Commun. 2011;16(3):89-102.

17. Press VG, Arora VM, Shah LM, Lewis SL, Charbeneau MS, Naurekas ET, et al. Teaching the use of respiratory inhalers to hospitalised patients with asthma or COPD - a randomized trial. J Gen Intern Med. 2012;27(10):1317-25.

18. St. Vincent's Hospital Melbourne. The Hepatitis B Story. Melbourne, VIC (Australia): St. Vincent's Hospital Melbourne (AU); 2015 Dec [cited 12 July 2018]. Available from: https:/www.svhm.org.au/ArticleDocuments/2305/ English-A5-Hep-B-Story-Web.pdf.aspx?embed=y

19. Jager AJ, Wynia MK. Who gets a teach-back? Patient-reported incidence of experiencing a teach-back. J Health Commun. 2012;17(3):294-302.

20. DeWalt D, Callahan LF, Hawk VH, Broucksou KA, Hink A, Rudd R, et al. Health Literacy Universal Precautions Toolkit. 2010. Available at: http://www.ahrq. gov/qual/literacy/healthliteracytoolkit.pdf.

21. Adams R, Stocks NP, Wilson DH, Hill CL. Health literacy - a new concept for general practice? Aust Fam Physician. 2009;30(3):144-7.

22. Nutbeam D. Health promotion glossary. Health Pro Intern. 1998;13:349-64.

23. Guirgis M, Nusair F, Bu YM, Yan K, Zekry AT. Barriers faced by migrants in accessing healthcare for viral hepatitis infection. Intern Med J. 2012;42(5):491-6.

24. Tran S, Bennett G, Richmond J, Phan D, et al. Teach-back is a simple communication tool that improves health literacy in people with chronic hepatitis B. J Gastroenterol Hepatol. 2017;32:83.

\section{Publisher's Note}

Springer Nature remains neutral with regard to jurisdictional claims in published maps and institutional affiliations.

Ready to submit your research? Choose BMC and benefit from:

- fast, convenient online submission

- thorough peer review by experienced researchers in your field

- rapid publication on acceptance

- support for research data, including large and complex data types

- gold Open Access which fosters wider collaboration and increased citations

- maximum visibility for your research: over $100 \mathrm{M}$ website views per year

At $\mathrm{BMC}$, research is always in progress.

Learn more biomedcentral.com/submissions 